\title{
Characterization of a strong and constitutive promoter from the Arabidopsis serine carboxypeptidase-like gene AtSCPL30 as a potential tool for crop transgenic breeding
}

Pingping Jiang ${ }^{1 \dagger}$, Ke Zhang $^{1 \dagger}$, Zhaohua Ding ${ }^{2 \dagger}$, Qiuxia He ${ }^{3}$, Wendi $\mathrm{Li}^{1}$, Shuangfeng Zhu' ${ }^{1}$, Wen Cheng ${ }^{2}$, Kewei Zhang ${ }^{1}$ and Kunpeng Li $^{1 *}$

\begin{abstract}
Background: Transgenic technology has become an important technique for crop genetic improvement. The application of well-characterized promoters is essential for developing a vector system for efficient genetic transformation. Therefore, isolation and functional validation of more alternative constitutive promoters to the CaMV35S promoter is highly desirable.

Results: In this study, a 2093-bp sequence upstream of the translation initiation codon ATG of ATSCPL30 was isolated as the full-length promoter (PD1). To characterize the AtSCPL30 promoter (PD1) and eight 5' deleted fragments (PD2-PD9) of different lengths were fused with GUS to produce the promoter::GUS plasmids and were translocated into Nicotiana benthamiana. PD1-PD9 could confer strong and constitutive expression of transgenes in almost all tissues and development stages in Nicotiana benthamiana transgenic plants. Additionally, PD2-PD7 drove transgene expression consistently over twofold higher than the well-used CaMV35S promoter under normal and stress conditions. Among them, PD7 was only 456 bp in length, and its transcriptional activity was comparable to that of PD2-PD6. Moreover, GUS transient assay in the leaves of Nicotiana benthamiana revealed that the 162-bp (- 456 - 295 bp) and 111-bp (-294 - $184 \mathrm{bp}$ ) fragments from the AtSCPL30 promoter could increase the transcriptional activity of mini35S up to $16-$ and 18 -fold, respectively.

Conclusions: As a small constitutive strong promoter of plant origin, PD7 has the advantage of biosafety and reduces the probability of transgene silencing compared to the virus-derived CaMV35S promoter. PD7 would also be an alternative constitutive promoter to the CaMV35S promoter when multigene transformation was performed in the same vector, thereby avoiding the overuse of the CaMV35S promoter and allowing for the successful application of transgenic technology. And, the 162- and 111-bp fragments will also be very useful for synthetic promoter design based on their high enhancer activities.
\end{abstract}

Keywords: AtSCPL30, CaMV35S, Constitutive promoter, GUS analysis, Nicotiana benthamiana, Stress treatment

\footnotetext{
* Correspondence: likp@sdu.edu.cn

${ }^{\dagger}$ Pingping Jiang, Ke Zhang and Zhaohua Ding contributed equally to this work.

${ }^{1}$ The Key Laboratory of Plant Cell Engineering and Germplasm Innovation, Ministry of Education, School of Life Science, Shandong University, Jinan, Shandong, China

Full list of author information is available at the end of the article
}

(c) The Author(s). 2018 Open Access This article is distributed under the terms of the Creative Commons Attribution 4.0 International License (http://creativecommons.org/licenses/by/4.0/), which permits unrestricted use, distribution, and reproduction in any medium, provided you give appropriate credit to the original author(s) and the source, provide a link to the Creative Commons license, and indicate if changes were made. The Creative Commons Public Domain Dedication waiver (http://creativecommons.org/publicdomain/zero/1.0/) applies to the data made available in this article, unless otherwise stated. 


\section{Background}

Transgenic technology has enabled incremental crop improvement by the introduction of specific genes or decreasing the expression of endogenous genes, including herbicide tolerance, insect resistance and tolerance to other stresses, to improve farming and production [1]. The major challenges in the successful application of transgenic technology are the precise control of transgenes or endogenous gene expression [2]. Appropriate promoters are crucial for the regulation of the transgenes expression at desired profile, thereby promoting the successful application of transgenic technology, while the number and type of promoters for plant genetic transformation are still quite limited [2-5]. Therefore, cloning and characterization of various promoters suitable for plant genetic transformation is highly desirable $[6,7]$.

Strong constitutive promoters can deliver a high-level expression of transgenes to almost all tissues and development stages in plants, which is particularly useful for the expression of herbicide tolerance, insect resistance and selectable marker genes [3]. For example, selectable marker gene systems are usually employed to avoid unnecessary and time-consuming screening for successful transgenic plants, which are more efficient at expressing selectable marker genes under the control of strong constitutive promoters [8,9]; The Bacillus thuringiensis gene has been widely used to protect plants against insects in a dosage-dependent manner $[10,11]$. Strong constitutive promoters facilitate the high expression of Bacillus thuringiensis gene, leading to an enhanced insect resistance [12], and the improtance of which has been verified by several studies in monocot or dicot plants, such as the cauliflower mosaic virus 35S (CaMV35S) promoter, the rice Actin1 and cytochrome $c$ gene promoter, and the maize ubiquitin1 promoter [13-18]. Among these promoters, the CaMV35S promoter and maize ubiquitin1 promoter are used most frequently to drive transgene expression in plants $[19,20]$. However, they also have some drawbacks. The CaMV35S promoter drives high-level expression of transgenes in dicot plants, while the maize ubiquitin1 promoter is more capable of driving gene expression in monocot plants [5]. Studies in rice have shown that the maize ubiquitin1 promoter could drive efficient expression of transgenes in young roots and leaves, while the activity drastically decreased with aging [2]. The maize ubiquitin1 promoter is inactive in some tissues in transgenic rice plants, such as anthers [21]. Due to the shortage of available promoters with the desired expression, the CaMV35S promoter is widely used to drive the expression of target genes and selectable marker genes in a single vector, such as pCAMBIA derivatives (http://www.cambia.org/ daisy/cambia/materials/vectors.html), which greatly increases the occurrence of homologous-dependent gene silencing $[7,9,22]$. In addition, the CaMV35S promoter is derived from plant viruses. A number of limitations have been found during its application, such as its suppression in plant-parasitic nematode feeding sites [23, 24], public perception concerns with the use of virus-derived promoters [25], the ability of a cell to recognize the sequence as foreign and inactivate it [26], and its poor performance in monocots. Compared with virus- or bacteria-derived promoters, the promoters of plant origin may be safer and reduce gene silencing concerns [2]. Although there is little evidence to support the hypothetical risk of viral recombination events between the viral promoters and host's DNA heavily utilized in plant genetic transformation [27-29]. The previous studies showed that a 19-bp palindromic sequence, including the TATA-box of CaMV35S promoter, acted as a recombination hotspot that was localized with the highly recombined region of $C a M V$ RNA to promote viral recombination in dicots [30]. Therefore, the virus-derived promoters may have a greater potential risk than the plant endogenous promoters in plant genetic engineering. However, the majority of reported endogenous plant promoters are typically long and weak in directing gene expression, which restricts their application [1]. A shortage of available plant-derived promoters for high-level stable expression of foreign genes limits the development of genetically modified crops through transgenic technology.

Serine carboxypeptidase (SCP) and serine carboxypeptidase-like (SCPL) proteins comprise a large family of protein hydrolyzing enzymes that catalyze the hydrolysis of the C-terminal peptide bond in proteins or peptides [31, 32]. Several SCP/SCPL genes have been cloned from many plants, including rice [33-35], Zea mays [36], Arabidopsis [37, 38], Pisum sativum [39], wheat [40], oats [41] and tobacco [42], The studies have shown that SCP/ SCPL genes are involved in a wide range of biological processes and are usually widely expressed in all tissues in higher plants. Among them, some members of SCP/ $S C P L$ are constitutively expressed, while some others are tissue-specifically expressed or induced by stress conditions. For example, Bienert et al. found that the serine carboxypeptidase genes NtSCP1 and NtSCP2 were widely expressed in the roots, stems, leaves and flowers of tobacco [42]; Liu et al. found that OsBISCPL1, a rice serine protein gene, was expressed in leaves, roots, stems and leaf sheaths [35]. The expression level of OsBISCPL1 was relatively high in leaves and leaf sheaths and relatively weak in stems [35]. The previous studies showed that the serine carboxypeptidase-like 30 (AtSCPL30; At4g15100) is highly expressed in roots, leaves and flowers of Arabidopsis thaliana [43, 44]. However, AtSCPL3O and its promoter region have not been characterized to date. Isolation and characterization of the AtSCPL30 promoter will provide novel insights into understanding the transcriptional regulation of AtSCPL30 and the promoter resources for crop genetic improvement by transgenic technology. 
In this study, we describe the isolation and functional validation of the AtSCPL3O promoter from Arabidopsis thaliana by deletion analysis in Nicotiana benthamiana transgenic plants. Our results showed that the AtSCPL3O promoter (PD1) and its 5' deletion fragments of different lengths (PD2-PD9) could confer strong and constitutive expression of $\beta$-glucuronidase (GUS) in almost all tissues and development stages in Nicotiana benthamiana transgenic plants. Among them, the abilities of PD2-PD7 to drive transgene expression were consistently more than twofold that of the CaMV35S promoter. The size of the PD7 fragment is only $456 \mathrm{bp}$ in length. It will be a very useful tool for crop transgenic breeding, which provides a plant-derived alternative constitutive strong promoter.

\section{Methods}

\section{Isolation of the AtSCPL30 promoter from Arabidopsis thaliana}

The 5' flanking sequence of AtSCPL30 (At4g15100) was retrieved from the TAIR database (http://www.ara bidopsis.org/). The forward and reverse primers (named $P_{\text {AtSCPLZOFR }}$, Table 1) were designed according to the AtSCPL30 sequence and its 5' flanking region. The 2181-bp fragment $(-2093 \sim+88$ bp; the "A" of the translation start codon "ATG" of AtSCPL30 was designated "+ 1") was amplified from Arabidopsis thaliana genomic DNA with the $P_{\text {AtSCPL3OFR }}$ primers and confirmed by sequencing. Finally, a 2093-bp fragment upstream of the translation start codon of AtSCPL3O was obtained by polymerase chain reaction (PCR) amplification using PD1FR primers (Table 1) and considered the full-length promoter (PD1).

\section{Bioinformatic analysis of the AtSCPL30 promoter sequence} The potential cis-acting elements in the 2093-bp (- 2093 $\sim-1 \mathrm{bp}$ ) fragment of AtSCPL30 promoter were analyzed with PLACE (http://www.dna.affrc.go.jp/PLACE/) [45] and PlantCARE (http://bioinformatics.psb.ugent.be/web tools/plantcare/html/) software [46], and were listed in Additional file 2: Figure S1 and Additional file 1: Table S1.

\section{Plasmid construction}

The AtSCPL30 promoter (PD1, - 2093 bp to $-1 \mathrm{bp}$ ) and eight $5^{\prime}$ deleted fragments (PD2-PD9) in different lengths (- 1479 bp, - 1135 bp, - 874 bp, - 731 bp, - 601 bp, 456 bp, -294 bp, and - 189 bp to -1 bp; Fig. 1a) were obtained by PCR amplification from the 2093-bp promoter region of AtSCPL3O using the oligonucleotide primers listed in Table 1. For the construction of AtSCPL30 promoter:: GUS vectors, each PCR product was ligated into the pCAMBIA1391Z plasmid (Cambia, Australia) with $\mathrm{BamHI} / \mathrm{NcoI}$ restriction sites and confirmed by sequencing and restriction digestion (Fig. 1b). The resulting plasmids were used for the transformation of Nicotiana benthamiana. The pCAMBIA1304 (Cambia, Australia), a GUS expression vector driven by the CaMV35S promoter, was used as a positive control.

The mini35S plasmid was obtained as described by Hou et al. [6]. The 162-bp (-456 - 295 bp), 111-bp $(-294 \sim-184$ bp $)$ and 273-bp $(-456 \sim-184$ bp $)$

Table 1 PCR primers used in the present study

\begin{tabular}{|c|c|c|}
\hline Name & Forward $\left(5^{\prime}-3^{\prime}\right)$ & Reverse $\left(5^{\prime}-3^{\prime}\right)$ \\
\hline$P_{\text {AtSCPL3OFR }}$ & ctaatctcaatgtttccgcctttc & cacatgaaaccatttctactaatat \\
\hline PD1FR & atcggatccctaatctcaatgtttccgc & attccatggttgaggctaggttttagtag \\
\hline PD2FR & atcggatccaagggaactacgcaaga & attccatggttgaggctaggttttagtag \\
\hline PD3FR & atcggatccctgetttcgatcatttc & attccatggttgaggctaggttttagtag \\
\hline PD4FR & atcggatccatggagttagagtttac & attccatggttgaggctaggttttagtag \\
\hline PD5FR & atcggatcctaagtcgatcaatccgc & attccatggttgaggctaggttttagtag \\
\hline PD6FR & atcggatccccgaatccacgaaac & attccatggttgaggctaggttttagtag \\
\hline PD7FR & atcggatccataggcaaccgtggact & attccatggttgaggctaggttttagtag \\
\hline PD8FR & atcggatccttatccctgtaaatcc & attccatggttgaggctaggttttagtag \\
\hline PD9FR & atcggatccgctaccaatttaccaca & attccatggttgaggctaggttttagtag \\
\hline$P_{\text {CaMV35SFR }}$ & aatggatccaagtctcaatageccttt & tgagaattccgtattggctagagcagc \\
\hline PD7-8FR & atcggatccataggcaaccgtggact & agcctgcagattcgaatgaattcgtatat \\
\hline PD8-9 FR & atcggatccttatccctgtaaatcct & aagctgcagggtagctttagtttattga \\
\hline PD7-9FR & atcggatccataggcaaccgtggact & aagctgcagggtagctttagtttattga \\
\hline HPTFR & cgtctgctgctccatacaa & tgtcctgcgggtaaatagc \\
\hline$P_{Z m U b i-1 F R}$ & gataagcttctgcagaagtaacaccaaacaatcg & agcggatccgcatgcctgcagtgcaactttatat \\
\hline
\end{tabular}

The underlined sites are the sites for the digestion of restriction enzymes BamHI. The underlined italicized sites are the sites for the digestion of restriction enzymes $\mathrm{Ncol}$. The sites in bold are the sitess for the digestion of restriction enzymes Pstl. The italicized site is the site for the digestion of restriction enzymes HindW 


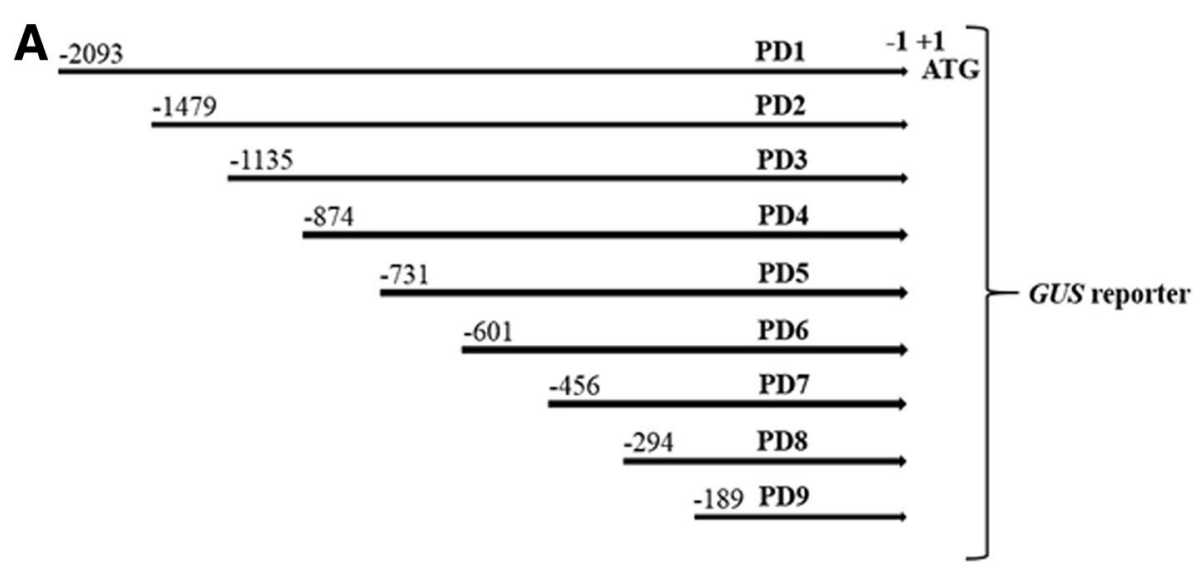

$\begin{array}{lllllllll}B & \text { PD1 } & \text { PD2 } & \text { PD3 } & \text { PD4 } & \text { PD5 } & \text { PD6 } & \text { PD7 PD8 } & \text { PD9 } \text { Marker }\end{array}$

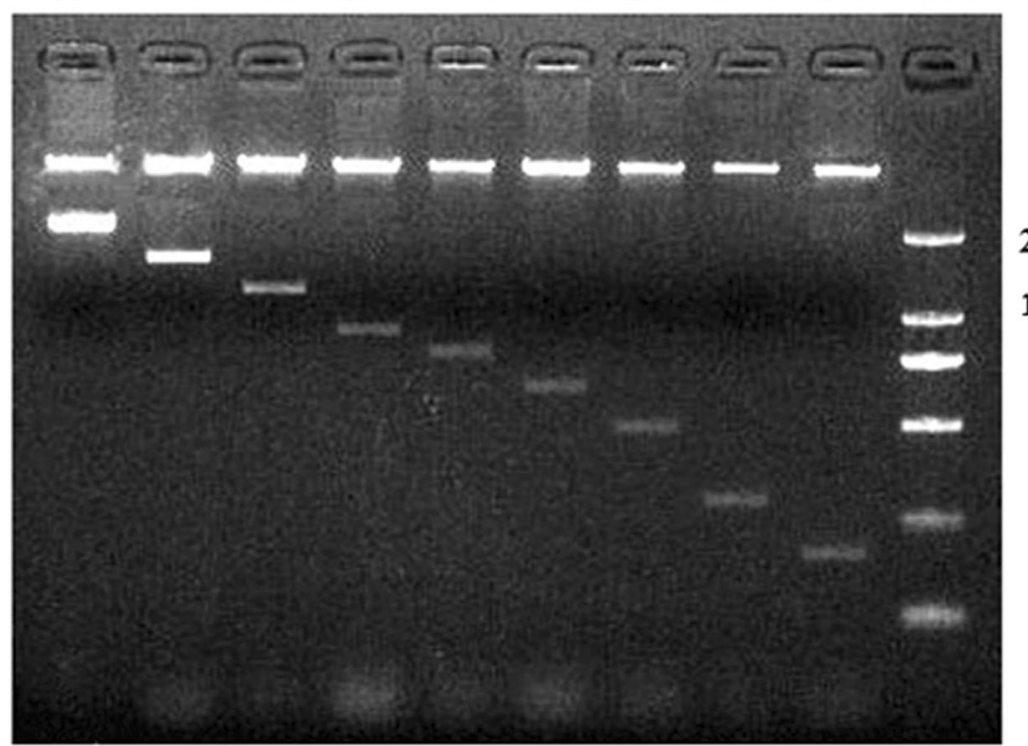

$2000 \mathrm{bp}$

$1000 \mathrm{bp}$

$750 \mathrm{bp}$

$500 \mathrm{bp}$

$250 \mathrm{bp}$

$100 \mathrm{bp}$

Fig. 1 The constructs of the AtSCPL30 promoter reporter plasmids and the picture of restriction digestion analysis. a The AtSCPL30 promoter (PD1) and eight 5' deleted fragments (PD2-PD9) were ligated upstream of the GUS reporter gene of the pCAMBIA1391Z vector. The numbers indicate the nucleotide position from the translational initiate code ATG (A as +1$)$. $\mathbf{b}$ The fused plasmids were confirmed by restriction digestion analysis with BamHI/Ncol. Marker, DL2000

fragments from the AtSCPL30 promoter sequence (the "A" of the translation start codon "ATG" was designated "+ 1") were amplified by PCR using the primers PD7-8FR, PD89FR and PD7-9FR, respectively (Table 1), and then was confirmed by sequencing. Finally, the obtained 162-bp, 111-bp and 273-bp fragments were ligated into the mini35S plasmid with the BamHI/Pst I restriction sites, respectively. The resulting plasmids were designated the PD7 8-mini35S, PD8 9-mini35S and PD7 9-mini35S and used for the transient assays in Nicotiana benthamiana.

Culture and genetic transformation of Nicotiana benthamiana The surface sterilization of Nicotiana benthamiana seeds, germination and culture of aseptic seedlings were performed as described by Hou et al. [6]. The leaves of 6-week-old seedlings were used for transformation.

The recombinant constructs PD1-PD9 and pCAMBIA1304 were transferred into Agrobacterium tumefaciens GV3101. The transformation of Nicotiana benthamiana were as described previously by Voelker et al. [47]. The transformed shoots were screened on MS medium containing $1.0 \mathrm{mg} / \mathrm{L}$ 6-benzylaminopurine, $0.1 \mathrm{mg} / \mathrm{L}$ indole-3-acetic acid, $300 \mathrm{mg} / \mathrm{L}$ cefotaxime and $15 \mathrm{mg} / \mathrm{L}$ hygromycin $\mathrm{B}$. Regenerated shoots were rooted on MS medium supplemented with $200 \mathrm{mg} / \mathrm{L}$ cefotaxime and $15 \mathrm{mg} / \mathrm{L}$ hygromy$\operatorname{cin} \mathrm{B}$. The regenerated seedlings were cultivated in nursery soil under $26-28{ }^{\circ} \mathrm{C}$ (day) $/ 20-22{ }^{\circ} \mathrm{C}$ (night) with a cycle of 16-h light $\left(230-260 \mu \mathrm{mol} \mathrm{m}{ }^{-2} \mathrm{~s}^{-1}\right)$. The T0 positive transformants were confirmed by PCR amplification 
(Additional file 3: Figure S2A) and GUS staining (Additional file 3: Figure S2B) as described by Hou et al. [6]. The T1-generation transgenic lines that displayed a $3: 1$ Mendelian segregation ratio by hygromycin $B$ resistance screening were used for propagation (Additional file 4: Figure S3). Finally, the homozygous transgenic lines of the T3 generation with a single copy of the promoter::GUS insert from the CaMV35S and AtSCPL30 promoter deletion vectors were selected for function analyses via segregation ratio analysis.

\section{$\mathrm{NaCl}, \mathrm{PEG}$ and low-temperature stress treatments}

PD1-PD9 and CaMV35S promoter transgenic and non-transgenic (WT) Nicotiana benthamiana seedlings were cultured as described by Hou et al. [6]. Finally, 60-day-old plants were subjected to $\mathrm{NaCl}$, PEG and low-temperature stress treatments with either two fully expanded detached-leaves in vitro or intact plants.

The intact plants or the leaf discs $0.5 \mathrm{~cm}$ in diameter were treated with: (i) $\mathrm{NaCl}(0$ and $200 \mathrm{mM})$ or polyethylene glycol (PEG) $6000(0$ and $18 \%, w / v)$ at $25^{\circ} \mathrm{C}$; or (ii) low temperature stress at $4{ }^{\circ} \mathrm{C}$ in the $1 / 2 \mathrm{MS}$ liquid medium for $24 \mathrm{~h}$, or $3,6,12,24,48$, and $72 \mathrm{~h}$, respectively. Leaf tissues were sampled for GUS staining immediately and frozen in liquid nitrogen for GUS fluorometric assays. At least three biological replicates for the independent experiment were performed.

\section{Histochemical and fluorometric GUS assays}

Three independent transgenic lines and at least five individual plants from each plasmid were used for the GUS expression assay. GUS Histochemical staining and fluorometric assays were carried out as described by Jefferson et al. with minor modifications [48]. The tissues were incubated in GUS staining solution containing $50 \mathrm{mM}$ sodium phosphate $(\mathrm{pH} \quad 7.0), \quad 0.5 \mathrm{mM}$ potassium ferrocyanide, $0.5 \mathrm{mM}$ potassium ferricyanide, $0.1 \%$ Triton X-100, 10 mM EDTA, and 1 mM X-Gluc (Sangon, Shanghai, China). Following vacuum infiltration, the samples were incubated at $37^{\circ} \mathrm{C}$ for $3 \mathrm{~h}$. After staining, the tissues were bleached with $70 \%$ ethanol and photographed (Sony DSC-F828 digital camera).

The tissues were homogenized in a $4{ }^{\circ} \mathrm{C}$ extraction buffer containing $50 \mathrm{mM}$ sodium phosphate ( $\mathrm{pH} 7.0)$, $10 \mathrm{mM}$ DL-dithiothreitol, $0.1 \%$ sodium lauryl sarcosine, $10 \mathrm{mM}$ EDTA and $0.1 \%$ Triton X-100 for GUS fluorometric assays. After centrifugation at $10000 \mathrm{~g}$ for $15 \mathrm{~min}$ at $4{ }^{\circ} \mathrm{C}$, the activity of the supernatant was detected in an assay buffer containing $1 \mathrm{mM}$ 4-methylumbelliferyl-b-glucuronide (4-MUG, Sigma, USA) at $37{ }^{\circ} \mathrm{C}$. The reaction was terminated by the addition of $200 \mathrm{mM} \mathrm{Na}_{2} \mathrm{CO}_{3}$ to a final concentration of $180 \mathrm{mM}$. The fluorescence was quantified with a fluorescence spectrophotometer (HITACHI F-4600, Japan) at excitation and emission wavelengths of $365 \mathrm{~nm}$ and
$455 \mathrm{~nm}$, respectively. The protein concentration of the supernatant from each sample was determined as described by Bradford [49]. The GUS activity was normalized with five 4-MU standards (10 mM, $1 \mathrm{mM}, 100 \mathrm{nM}$, $50 \mathrm{nM}$, and $10 \mathrm{nM}$ ) and calculated as nmol of 4-MU per mg protein per minute under control conditions.

\section{GUS transient assay in tobacco leaves}

A GUS transient assay was performed using the leaves from sixty-day-old Nicotiana benthamiana plants as described by Yang et al. [50]. A. tumefaciens GV3101 harboring mini35S, PD7 8-mini35S, PD8 9-mini35S and PD7 9-mini35S plasmids were grown on YEP liquid medium containing $50 \mathrm{mg} / \mathrm{L}$ kanamycin and rifampin at $28{ }^{\circ} \mathrm{C}$ for $18 \mathrm{~h}$. The harvest and resuspension of bacteria and infection of the leaves were performed as described by Hou et al. [6]. Finally, the leaf discs from twenty-three infiltrated plants were used for GUS fluorometric assays and GUS staining. The entire experiment was repeated three times.

\section{Transformation of maize calli}

The sequence of the maize ubiquitin1 promoter was amplified from vector pTCK303 with the $P_{Z m U b i-1 F R}$ primers (Table 1) [51]. The amplified fragment was subsequently constructed into the vector pCAMBIA1391Z with HindW/BamHI restriction sites and confirmed by sequencing. The resulting plasmid pCAMBIA1391Z-Ubi-GUS was used as a positive control.

The constructs PD1, PD2, PD7 and pCAMBIA1391ZUbi-GUS were transferred into Agrobacterium tumefaciens strain LB4404 using a freeze-thaw method. The transgenic maize calli were obtained by Agrobacterium LB4404-mediated transformation of embryogenic type II calli from immature embryos of maize inbred line Qi319 as described by Quan et al. [52]. Transformed calli were selected on medium containing $15 \mathrm{mg} / \mathrm{L}$ hygromycin B for 2 weeks. Resistant calli were used for GUS histochemical staining.

\section{Data analysis}

All GUS fluorometric assays were repeated at least three times. The results were expressed as the mean values \pm SD (standard deviation). Student's t test $(n=3, P<0.05$; Sigmaplot 12.0) at a $95 \%$ confidence level was used to test for statistical significance.

\section{Results}

Isolation of AtSCPL30 promoter and sequence analysis

Based on the public sequence from TAIR (http://www.arabi dopsis.org/), the 2093-bp promoter sequence of AtSCPL30 (At4g15100) upstream of the start codon ATG was isolated from Arabidopsis thaliana genomic DNA. The AtSCPL30 promoter sequence was analyzed through online programs PLACE and PlantCARE. The results showed that the 
2093-bp promoter sequence contains twenty-six types of putative cis-acting elements (Additional file 2: Figure S1 and Additional file 1: Table S1), including CAAT-box and TATA-box core cis-acting elements. Moreover, some cisacting elements that enable the tissue-specific, inducible, and enhanced or suppressed expression of AtSCPL3O were identified, including five types of light-responsive elements (TCT-motif, GAG-motif, GATABOX, G-box and GT1CONSENSUS), six kinds of phytohormone-responsive elements (ABRE, NTBBF1ARROLB, WRKY71OS, TCAelement, SARE and CATATGGMSAUR), two kinds of elicitor-responsive elements (Box-W1 and EIRE), two kinds of elements required for tissue- or organ-specific expression (OSE1ROOTNODULE and TATCCAOSAMY), several elements involved in defense or stress (HSE, PREATPRODH, LTR, GT1GMSCAM4 and TC-rich repeats), five new signal element (POLASIG1), A negative cis-element conserved in plastid-related genes (S1FBOXSORPS1L21), five elements required for etiolation-induced expression of erd1 (ACGT ATERD1) and 14 potential core sites required for the binding of Dof transcription factors that regulate the intensity of gene expression (DOFCOREZM). These potential elements may be related to the functional properties of the AtSCPL30 promoter.

\section{Expression patterns and activities of the AtSCPL30 promoter and its $5^{\prime}$ deletion segments in Nicotiana} benthamiana transgenic plants under normal conditions To profile the expression of Nicotiana benthamiana transgenic plants driven by PD1-PD9 and the CaMV35S promoter under normal conditions, the radicle of seeds germinated for 2 days; 7-, 14- and 21-day-old seedlings; the roots, stems, and leaves of 60- and 90-day-old plants; and the flowers, fruits and seeds from 90-day-old plants were subjected to GUS histochemical staining (Fig. 2). Our results showed that PD1-PD9 and the CaMV35S promoter were able to efficiently drive the expression in almost all the tissues of transgenic Nicotiana benthamiana at different developmental stages, except for the petals of PD8 and PD9.

Because of the original high GUS expression levels in various tissues of PD1-PD9 and CaMV35S promoter transgenic plants of Nicotiana benthamiana, it is difficult to see a significant difference in expression intensity just by GUS histochemical staining (Fig. 2). To clarify the difference in GUS expression levels between the series of mutants and CaMV35S promoter transgenic Nicotiana benthamiana, fluorometric GUS assays of the roots, stems and leaves from 60-day-old transgenic plants were carried out (Table 2). The results showed that the GUS activities in the roots, stems and leaves of PD1-PD9 and CaMV35S promoter transgenic plants were higher than $80 \mathrm{nmol}$ 4-MU/min $\cdot \mathrm{mg} \bullet$ protein under normal conditions, and there was no significant difference between the three tissues of each construct (Table 2). Among them, the GUS activity of PD1 (the full-length promoter) transgenic plants was approximately 1.7-fold that of the CaMV35S promoter; the GUS activities of PD2-PD7 were twofold higher than that of the CaMV35S promoter; GUS staining intensity of PD8 and PD9 was approximately 1.2-fold and $70 \%$ of CaMV35S promoter transgenic plants, respectively. Together, the above results indicated that the series of mutants of the AtSCPL30 promoter were capable of directing GUS expression in almost all tissues at different developmental stages of transgenic Nicotiana benthamiana under normal conditions; specifically, the PD2-PD7 fragments were obviously higher than that of the CaMV35S promoter, showing a good potential for application in transgenic breeding.

\section{Characterization of the AtSCPL30 promoter and its 5' deletion segments in transgenic Nicotiana benthamiana plants under stress conditions}

Under natural conditions, plants often suffer from adversities such as salinity, drought and low temperature. The sequence of the AtSCPL30 promoter contained some potential elements involved in low-temperature responsiveness, salt-induced gene expression and osmotic stress. Further work was carried out to investigate whether the AtSCPL30 promoter and its $5^{\prime}$ deletion segments were active under various stress conditions. The abilities of PD1-PD9 to drive gene expression were detected in the leaves of Nicotiana benthamiana transgenic plants under low-temperature, salt- or osmotic-stress treatments. Positive (CaMV35S promoter transgenic plants) and negative (non-transformed wild-type plants) control materials were also treated in parallel.

The detached leaf discs from sixty-day-old transgenic plants were treated under $200 \mathrm{mM} \mathrm{NaCl}$ (Additional file 5: Figure S4), 18\% PEG 6000 ( $w / v$, Additional file 6: Figure S5) or low temperature $\left(4{ }^{\circ} \mathrm{C}\right.$, Additional file 7: Figure S6) for 3, $6,12,24,48$, and $72 \mathrm{~h}$, respectively. The intensity of GUS staining in the leaf discs of PD1-PD9 and CaMV35S promoter transgenic plants were no obvious differences between the control and stress-treated groups. However, it is worth noting that PD1-PD9 was still able to confer high levels of GUS expression during the $\mathrm{NaCl}$, PEG and $4{ }^{\circ} \mathrm{C}$ treatments.

To further confirm the above results, the stress treatments involving whole plants of sixty-day-old transgenic and non-transformed wild-type Nicotiana benthamiana were also carried out. Based on the experiment results of detached-leaves, the Nicotiana benthamiana plants were chosen to treat $24 \mathrm{~h}$ under $200 \mathrm{mM} \mathrm{NaCl}, 18 \%$ PEG $6000(w / v)$ or $4{ }^{\circ} \mathrm{C}$ condition. GUS staining and fluorometric assay showed that the promoter activities of PD1-PD9 were indeed not induced by salt stress, osmotic stress and $4{ }^{\circ} \mathrm{C}$ treatments, whereas the AtSCPL3O 


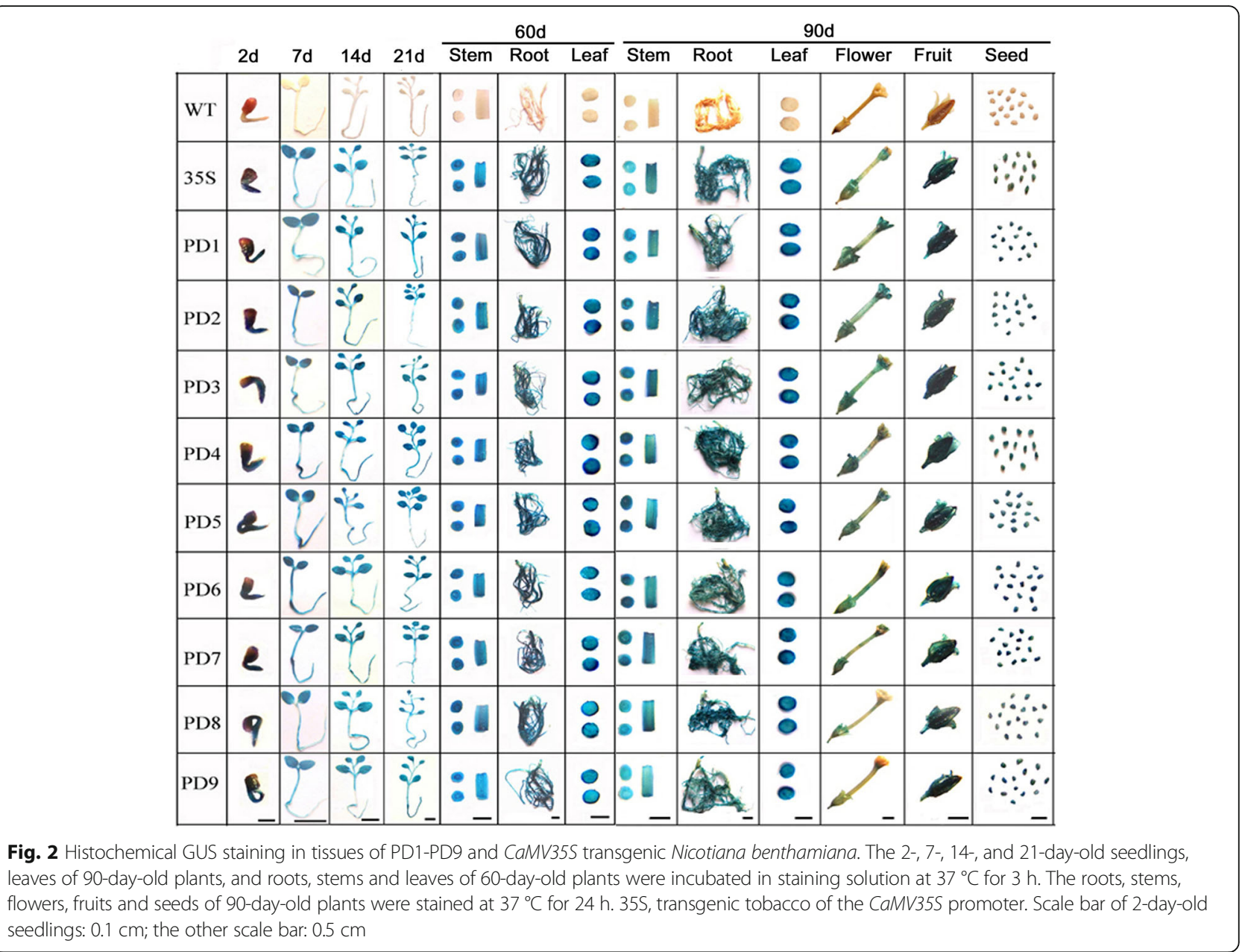

Table 2 GUS fluorescent quantitative analysis of PD1-PD9 and CaMV35S promoter Nicotiana benthamiana transgenic plants under normal conditions

\begin{tabular}{llll}
\hline Item & \multicolumn{3}{l}{ GUS activities (nmol 4-MU/min•mg・protein) } \\
\cline { 2 - 4 } & Root & Stem & Leaf \\
\hline CaMV35S & $125.79 \pm 9.81 \mathrm{~b}$ & $125.88 \pm 2.63 \mathrm{~b}$ & $124.88 \pm 2.61 \mathrm{~b}$ \\
PD1 & $210.54 \pm 4.74 \mathrm{~d}$ & $194.58 \pm 7.85 \mathrm{~d}$ & $207.10 \pm 9.23 \mathrm{~d}$ \\
PD2 & $273.93 \pm 7.79 \mathrm{ef}$ & $280.61 \pm 10.46 \mathrm{ef}$ & $292.39 \pm 2.01 \mathrm{f}$ \\
PD3 & $268.05 \pm 4.7 \mathrm{e}$ & $265.60 \pm 3.74 \mathrm{e}$ & $267.71 \pm 9.61 \mathrm{e}$ \\
PD4 & $276.26 \pm 10.38 \mathrm{ef}$ & $279.41 \pm 6.71 \mathrm{ef}$ & $276.02 \pm 7.38 \mathrm{ef}$ \\
PD5 & $263.96 \pm 8.52 \mathrm{e}$ & $274.32 \pm 6.78 \mathrm{ef}$ & $264.23 \pm 2.18 \mathrm{e}$ \\
PD6 & $265.58 \pm 9.47 \mathrm{e}$ & $278.20 \pm 3.21 \mathrm{ef}$ & $260.38 \pm 7.03 \mathrm{e}$ \\
PD7 & $270.56 \pm 2.16 \mathrm{ef}$ & $267.41 \pm 3.55 \mathrm{e}$ & $259.17 \pm 5.14 \mathrm{e}$ \\
PD8 & $140.01 \pm 9.80 \mathrm{c}$ & $150.33 \pm 4.47 \mathrm{c}$ & $145.41 \pm 9.53 \mathrm{c}$ \\
PD9 & $91.62 \pm 9.78 \mathrm{a}$ & $82.56 \pm 6.13 \mathrm{a}$ & $93.46 \pm 6.23 \mathrm{a}$ \\
\hline
\end{tabular}

Values are means \pm SD from 15 independent transgenic plants (5 individual plants/line, 3 lines for each construct). Different lowercase letters indicate significant differences at $P<0.05$ promoter and its $5^{\prime}$ deletion segments were capable of maintaining a high-level expression of the GUS gene under severe stress conditions (Fig. 3). Thereby, PD1-PD9 can efficiently drive the expression of foreign genes both before and after stresses. Notably, the PD2-PD7 fragments exhibited higher levels of promoter activity in Nicotiana benthamiana transgenic plants before and after the stress treatments compared to the full-length promoter (PD1) and PD8 and PD9 fragments, which were twofold higher than those of the CaMV35S promoter (Fig. 3b). Among them, PD7 was only $456 \mathrm{bp}$ in length, and its promoter activity was comparable to that of PD2-PD6 (Fig. 3b). Therefore, PD7 may be the core functional segment that confers strong constitutive expression of the AtSCPL30 promoter. It could be of great use to drive transgene expression based on its expression patterns, promoter activity, stability and small size.

The 162-bp, 111-bp and 273-bp fragments all contribute significantly to gene expression

The abilities of PD8 and PD9 to drive gene expression were significantly lower than that of PD2-PD7 in both 


\begin{tabular}{|c|c|c|c|c|c|c|c|c|c|c|c|}
\hline $\mathbf{A}$ & WT & $35 \mathrm{~S}$ & PD1 & PD2 & PD3 & PD4 & PD5 & PD6 & PD7 & PD8 & PD9 \\
\hline Control & 00 & 00 & 00 & O & 00 & 00 & 00 & 00 & 00 & 00 & 00 \\
\hline $0 \mathrm{mM} \mathrm{NaCl}$ & 0.0 & 00 & 00 & 00 & 00 & 00 & 00 & 00 & 00 & 00 & 00 \\
\hline$\%$ PEG 6000 & OC & 00 & 00 & 00 & 00 & 00 & 00 & 00 & 00 & 00 & 00 \\
\hline $4^{\circ} \mathrm{C}$ & 80 & 00 & 00 & 00 & 00 & 00 & 00 & 00 & 00 & 00 & 00 \\
\hline
\end{tabular}

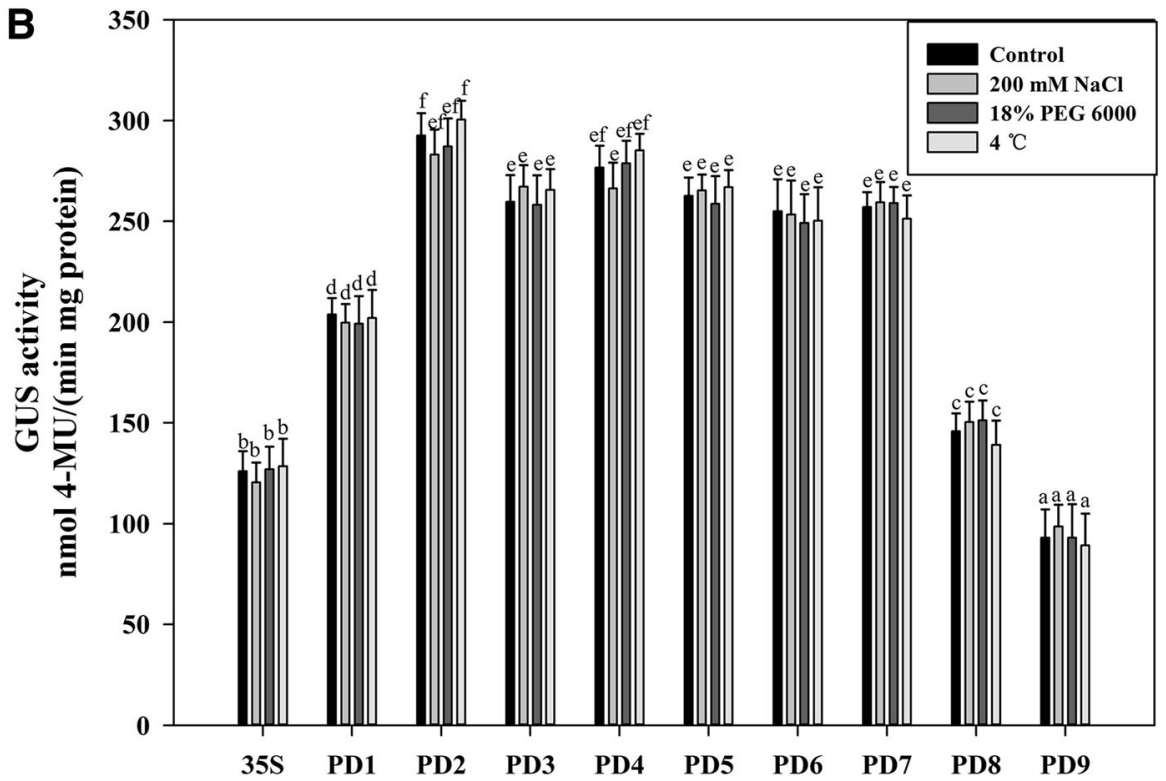

Fig. 3 GUS staining and fluorescent quantitative analysis of PD1-PD9 Nicotiana benthamiana transgenic plants under normal and stress conditions. For $\mathrm{NaCl}$ and PEG treatments of whole plants, 60 -day-old transgenic plants were immersed in a liquid 1/2 MS medium supplemented with either $200 \mathrm{mM}$ $\mathrm{NaCl}$ or $18 \%(\mathrm{~W} / \mathrm{V})$ PEG 6000 at $25^{\circ} \mathrm{C}$ for $24 \mathrm{~h}$. For $4{ }^{\circ} \mathrm{C}$ treatment of whole plants, 60 -day-old plants were immersed in a liquid $1 / 2 \mathrm{MS}$ medium at $4{ }^{\circ} \mathrm{C}$ for $24 \mathrm{~h}$. The plants grown in liquid $1 / 2 \mathrm{MS}$ medium at $25^{\circ} \mathrm{C}$ for $24 \mathrm{~h}$ were treated as a control. a GUS histochemical staining. The leaves of PD1-PD9 and CaMV35S promoter transgenic plants were stained for $3 \mathrm{~h}$. Samples were then observed and photographed after decolorization. $\mathbf{b}$ GUS activity assays of leaves. Values represent the means \pm SD from 15 independent transgenic plants (5 individual plants/line, 3 lines for each construct). Different lowercase letters above the bars indicate significant differences at $P<0.05$

before and after stresses (Table 2 and Fig. 3b). The promoter activity of PD8 was approximately $60 \%$ of that of PD7. The ability of PD9 to initiate gene expression was approximately $65 \%$ of the PD8 and 35\% of the PD7. The results suggested that the 162-bp fragment $(-456$ $\sim-295 \mathrm{bp})$, the 111-bp fragment $(-294 \sim-184 \mathrm{bp})$, and the 273-bp sequence $(-456 \sim-184 \mathrm{bp})$ may be able to promote gene expression. The 162-, 111- and 273-bp fragments were fused with mini35S $(-46 \sim+$ $10 \mathrm{bp}$ ) to drive GUS expression (Fig. 4a and b). The GUS transient assay in leaves of Nicotiana benthamiana plants showed that the 162-, 111- and 273-bp fragments increased the ability of mini35S to drive GUS expression by 16-, 18- and 22-fold, respectively (Fig. 4c and d). These segments will provide a sequence source for the artificial modification of promoters in the future.

\section{Detection of promoter activities of PD1, PD2 and PD7 in maize calli}

To preliminarily evaluate its application in the genetic transformation of monocots, the full-length promoter PD1, the fragments of PD2 and PD7, and the maize ubiquitin1 promoter (positive control) were selected to construct into the vector pCAMBIA1391Z driving the expression of GUS and introduced into maize calli. GUS histochemical staining showed that the PD2 and PD7 fragments seem to have a higher ability to drive gene expression than the maize ubiquitin1 promoter in maize calli (Fig. 5).

\section{Discussion}

Promoters play important roles in initiating gene transcription and regulating the expression of transgenes. Therefore, a good knowledge of promoter transcriptional activities and expression patterns is necessary for the successful application of transgenic breeding and gene function studies [5, 53]. In this study, the AtSCPL30 promoter from Arabidopsis thaliana was isolated and characterized by deletion analysis in Nicotiana benthamiana transgenic plants. We found that the AtSCPL30 promoter (PD1) and its 5' deletion fragments (PD2-PD9) were ubiquitously expressed in different tissues of Nicotiana benthamiana and retained their activities during high 


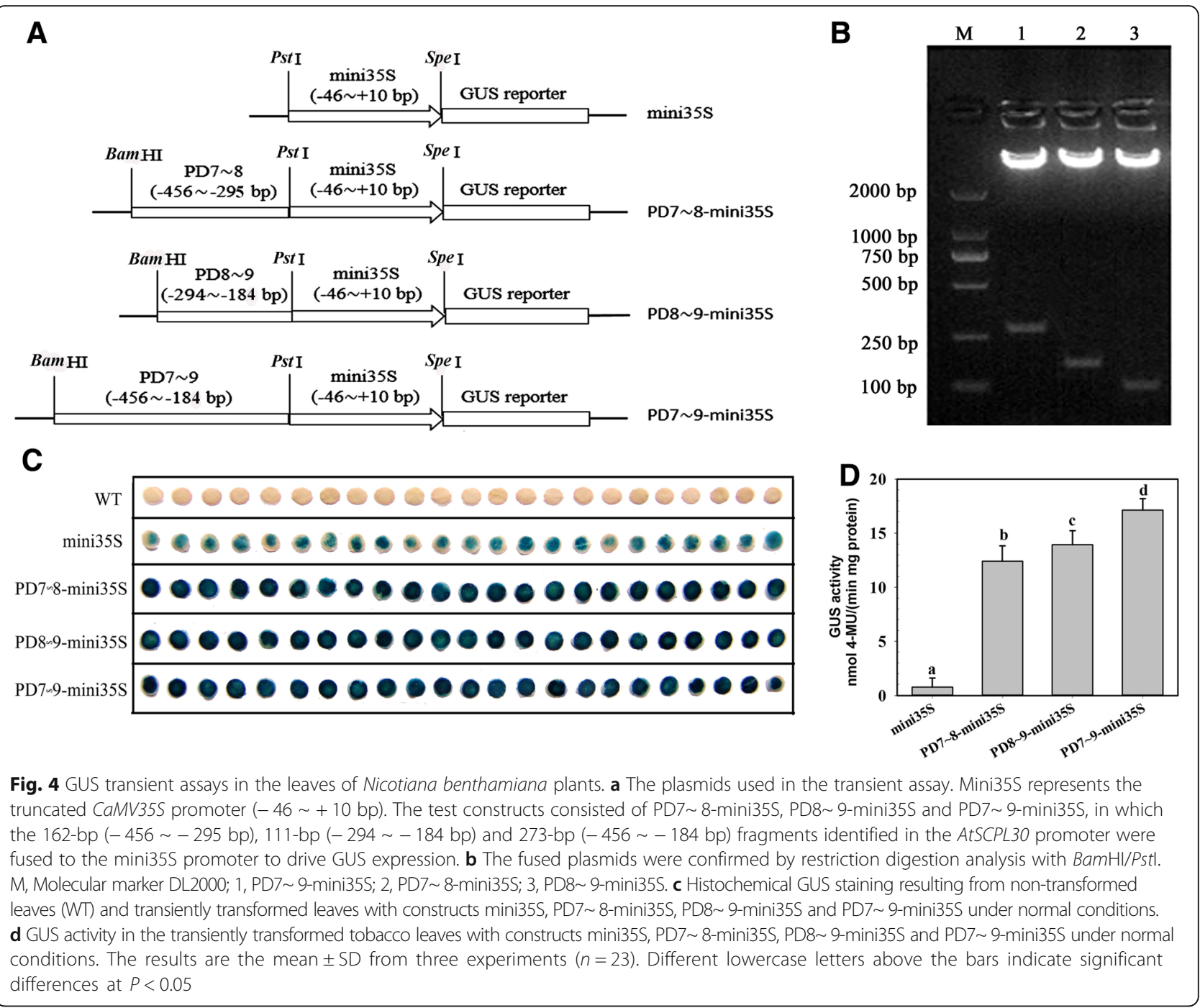

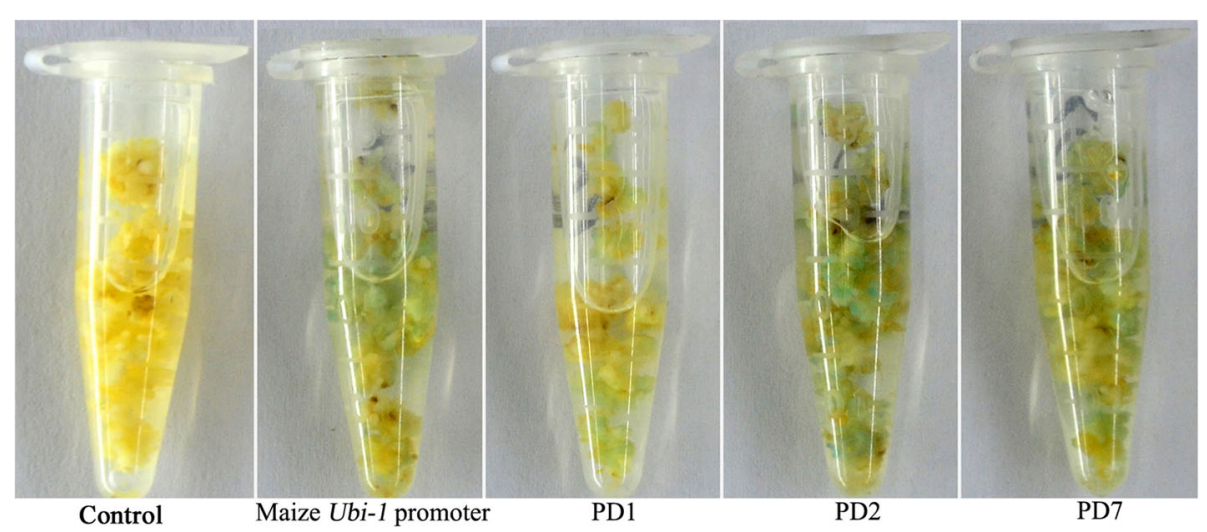

Fig. 5 GUS histochemical staining of transformed maize calli. Resistant calli were incubated in staining solution at $37^{\circ} \mathrm{C}$ for $24 \mathrm{~h}$. Finally, the samples were observed and photographed after decolorization 
salt, osmotic stress and low-temperature treatment. Finally, a 456 bp (PD7) core functional segment of the AtSCPL30 promoter was identified. The promoter activity of PD7 was higher than that of PD1, PD8 and PD9 and comparable to that of PD2-PD6, which is more than twofold higher than the CaMV35S promoter in different tissues of Nicotiana benthamiana under normal and stress conditions (Fig. 3b). Unlike the CaMV35S promoter from plant viruses, PD7 is a small plant endogenous constitutive promoter. Thus, it has the advantage of biosafety and reduces the probability of transgene silencing and the vector size, which is beneficial for genetic transformation [2]. Moreover, the stress adaptability of crops is quite complex. Single transgene introduction may not be sufficient to improve crop adaptability under natural conditions. However, multiple transgenes are introduced into plants and their expression is regulated using the same promoter in the construct, such as the CaMV35S promoter, which will greatly increase the occurrence of homologous-dependent gene silencing [3, 54]. Therefore, isolation and functional validation of more alternative constitutive promoters to the CaMV35S promoter is highly desirable. PD7 is an alternative constitutive strong promoter to the CaMV35S promoter and will be a very useful tool for transgenic breeding.

Promoters usually regulate the intensity of gene expression through the interaction of some specific cis-acting elements on the sequence with its interacting proteins, such as transcription factors. PD7 has very high promoter activity in Nicotiana benthamiana transgenic plants, while the deletion of the 163-bp fragment $(-456 \sim-294 \mathrm{bp})$ between PD7 and PD8 and the 106-bp fragment (-294 - 189 bp) between PD8 and PD9 resulted in a significant decrease in GUS activity (Fig. 3b). The results showed that these fragments mediated transcriptional enhancement and contributed to the strong promoter activities of PD2-PD7 fragments in Nicotiana benthamiana transgenic plants. The GUS transient assay in the leaves of 60-day-old Nicotiana benthamiana plants also showed that they have a strong ability to enhance gene expression (Fig. 4c and d). Bioinformatic analysis determined that the PD7 sequence, including the 163-bp and 106-bp regions, contains several elements (such as six CAAT-box and five DOFCOREZM domains) related to enhancing gene expression (Fig. 6). The CAAT-box is a common cis-acting element in promoter and enhancer regions that typically exhibits a putative effect in enhancing gene expression. DOFCOREZM is one of the binding site of Dof proteins $[55,56]$. Dof1 and Dof2 have been find to regulate the expression of multiple genes involved in carbon metabolism in maize, such as Dof1 can bind to the promoter of both cytosolic orthophosphate kinase (CyPPDK) and a non-photosynthetic PEPC gene to enhance their expression [57]. It has been confirmed that the Dof factor binding sites in subdomain B4 of the CaMV35S promoter are important and contribute to its promoter activity [20]. Indeed, much of the fine-tuning of gene expression is controlled by sequence-targeted enhancer-binding proteins or transcription factors, which bind to cis-elements within the promoter [2]. Based on the above results, we speculated that the CAAT-box and DOFCOREZM elements may be important factors contributing to the high promoter activity of PD7 and enhancer activities of the 162-bp and 111-bp fragments. Moreover, the deletion of the 615-bp (-2093 -1479) sequence between PD1 and PD2 resulted in a significant increase of GUS activity (PD2-PD7) in Nicotiana benthamiana transgenic plants. The results showed that the 615-bp sequence mediates the transcriptional repression and contributes to relatively weak promoter activity of PD1 compared to PD2-PD7. We think that the 615-bp fragment may contain cis-acting elements that inhibit gene expression. The deletion of the 163-bp fragment (-456 - 294 bp) between PD7 and PD8 causes PD8 and PD9 to not effectively drive gene expression in petals (Fig. 2). The results suggested that the 163-bp sequence contains the elements required for petal tissue-specific expression and contributes to promoter activity of PD1-PD7 fragments in petals of Nicotiana benthamiana.

In addition, the expression pattern and transcriptional activity of promoters may have obvious differences in dicot and monocot. The CaMV35S promoter is a widely used constitutive promoter conferring the strong expression of transgenes in dicots, while the ubiquitin promoter usually drives gene expression more efficiently in monocots than the CaMV35S promoter. For example, the maize ubiquitin1 promoter conferred gene expression up to or over tenfold higher than the CaMV35S promoter in rice, maize, wheat and barley, but its ability to drive gene expression in tobacco protoplasts was less than one-tenth of that of the CaMV35S promoter $[4,58,59]$. However, there are also some promoters that displayed high promoter activity in both monocots and dicots. For example, the small AtCTTP promoter $(0.3 \mathrm{~kb})$ displayed high transcriptional activities in creeping bentgrass (monocot) and Arabidopsis (dicot) [3]. The results suggested that the small AtCTTP promoter could be used in both monocot and dicot plant transgenic breeding. In this study, we identified PD2-PD7 fragments from the AtSCPL30 promoter that conferred strong and constitutive gene expression in Nicotiana benthamiana (dicot), implying that these fragments would be very useful tools for transgenic breeding in dicot. Using PD2 and PD7 fragments to drive GUS expression in maize calli, the results showed that they appeared to have higher promoter activities than maize ubiquitin1 promoter (Fig. 5). Further characterization of the expression patterns and transcriptional activities of PD2 and PD7 fragments in maize and evaluation of their 


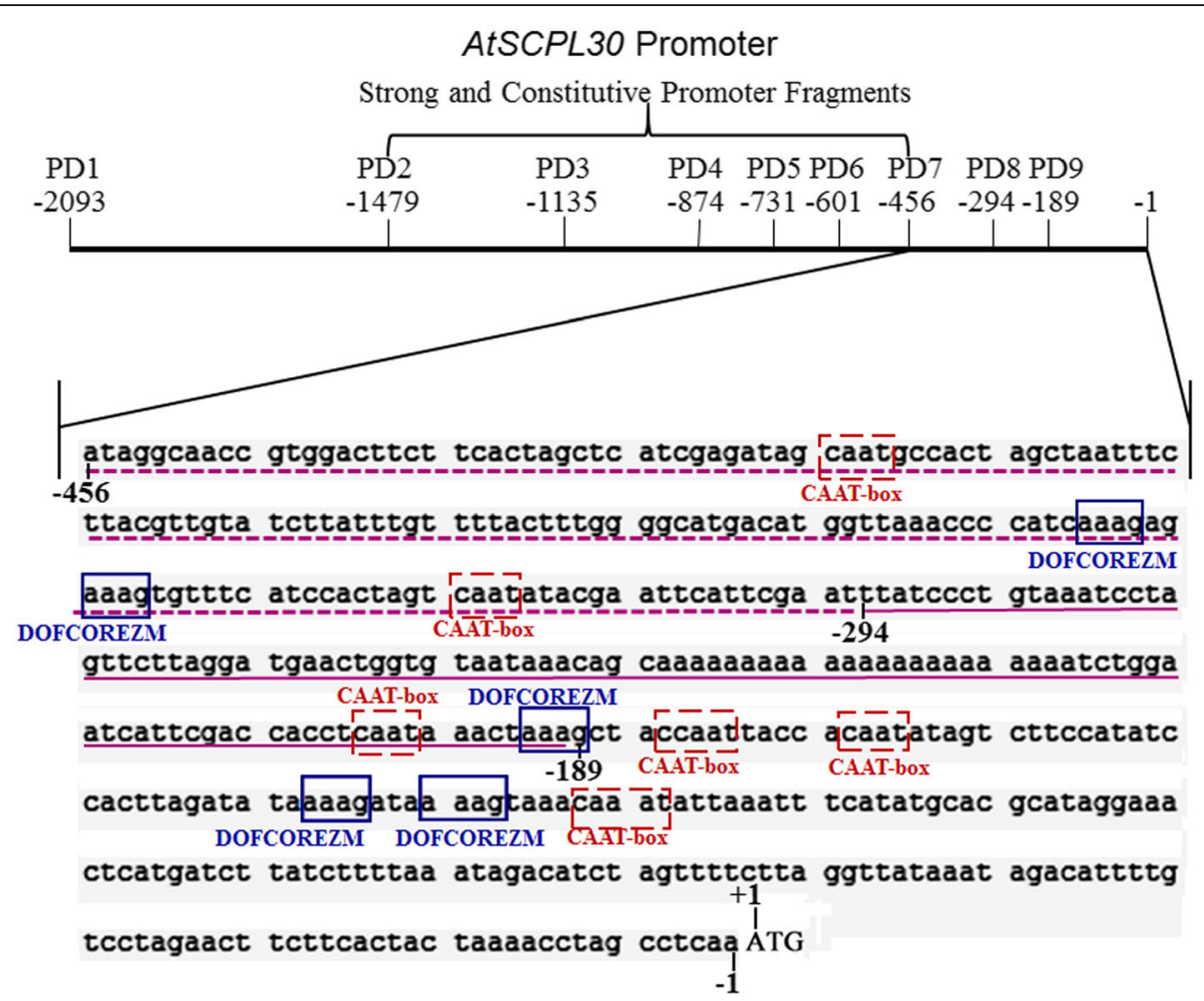

Fig. 6 Diagrams of PD7 promoter fragment and the 163- and 106-bp fragments for enhanced gene expression. Potential cis-acting elements associated with increased gene expression in the PD7 sequence predicted by PlantCARE and PLACE are shown on the border. CAAT box, common cis-acting element in promoter and enhancer regions; DOFCOREZM, core site required for binding of Dof proteins in maize. Dof1 and Dof2 transcription factors are associated with the expression of multiple genes involved in carbon metabolism in maize

application prospects in the transgenic breeding of monocot crops will also be meaningful in the future.

\section{Conclusions}

In this study, we isolated and characterized the promoter from the Arabidopsis serine carboxypeptidase-like gene (AtSCPL30) in Nicotiana benthamiana transgenic plants. By analyzing the AtSCPL30 promoter (PD1) and its 5' deleted fragments (PD2-PD9) under normal and stress conditions, we found that PD2-PD7 fragments could confer strong and constitutive expression of foreign genes and that their transcriptional activities were consistently over twofold higher than the well-used CaMV35S promoter in Nicotiana benthamiana transgenic plants (Fig. 3b). Among them, PD7 was only 456 bp in length, and its transcriptional activity was comparable to that of PD2-PD6. The PD7 sequence has also been shown to have very high transcriptional activity in maize calli (Fig. 5). Based on its expression patterns, promoter activity, small size and stability, the constitutive strong promoter (PD7) of plant origin is very useful for avoiding the repetitive usage of the virus-derived CaMV35S promoter and reducing the vector size and the probability of transgene silencing; thus, this promoter is beneficial for the successful application of transgenic technology.
Furthermore, the 162-bp (-456 - 295 bp), 111-bp $(-294 \sim-184 \mathrm{bp})$ and 273-bp $(-456 \sim-184 \mathrm{bp})$ fragments from the AtSCPL30 promoter were identified as the regions for enhancing gene expression by $5^{\prime}$ deletion mutation analysis, with a GUS transient assay in transformed leaves of Nicotiana benthamiana plants revealing that they do have very high enhancer activity. These sequences will provide important cis-regulatory elements for synthetic promoter design based on their enhancer activities.

\section{Additional files}

Additional file 1: Table S1. Potential cis-acting elements in the AtSCPL3O promoter sequence using the PLACE and PlantCARE databases. (DOCX $17 \mathrm{~kb}$ )

Additional file 2: Figure S1. Nucleotide sequence of the AtSCPL3O promoter. The "A" of the translation initiation code "ATG" of the AtSCPL3O was designated as "+ 1". Potential cis-acting elements underlined, different color or shown in the border. See Table S1 for descriptions of the elements. The arrow above the sequence indicates the start point of PD1 and different deletion fragments (PD2-PD9). (JPG $3013 \mathrm{~kb})$

Additional file 3: Figure S2. The PCR analysis and histochemical GUS staining of Nicotiana benthamiana transgenic plants. (A) Genomic PCR analysis of transformed plants using primers HPTFR (Table 1) designed for the hygromycin gene. Marker, DL2000 plus; +, the PCR result of plasmid pCAMBIA1391Z; WT, non-transformed control; 1-12, transformed T0 plants. (b) Histochemical GUS staining of transgenic plants. WT, non- 
transformed plants; 35S, transgenic plants of CaMV35S promoter; PD1PD9, transgenic plants of PD1 and eight truncated promoter fragments (PD2-PD9). (JPG $524 \mathrm{~kb}$ )

Additional file 4: Figure S3. The analysis of genetic segregation ratio in Nicotiana benthamiana transgenic plants by hygromycin resistance screening. (JPG $2214 \mathrm{~kb}$ )

Additional file 5: Figure S4. GUS staining of detached leaves of Nicotiana benthamiana transgenic plants under normal and salt-stress conditions. Ninety leaf discs (diameter $0.5 \mathrm{~cm}$ ) from fifteen 60-day-old individual plants (5 individual plants/ line, 3 lines for each construct) of PD1-PD9 and CaMV35S transgenic plants were incubated in liquid 1/2 MS medium supplemented with $200 \mathrm{mM} \mathrm{NaCl}$ at $25^{\circ} \mathrm{C}$ for $3,6,12,24,48$, and $72 \mathrm{~h}$; leaf discs floated in liquid $1 / 2 \mathrm{MS}$ medium were used as control. The leaf discs of PD1-PD9 and CaMV35S transgenic plants were then incubated in staining solution at $37^{\circ} \mathrm{C}$ for $3 \mathrm{~h}$. Finally, the samples were observed and photographed after decolorization. (JPG $3572 \mathrm{~kb}$ )

Additional file 6: Figure S5. GUS staining of detached leaves of Nicotiana benthamiana transgenic plants under normal and PEG treatment conditions. Ninety leaf discs (diameter $0.5 \mathrm{~cm}$ ) from fifteen 60-day-old individual plants (5 individual plants/line, 3 lines for each construct) of PD1-PD9 and CaMV35S transgenic plants were incubated in liquid 1/2 MS medium supplemented with $18 \%$ PEG6000 $(w / V)$ at $25^{\circ} \mathrm{C}$ for $3,6,12,24$, 48, and $72 \mathrm{~h}$; leaf discs floated in liquid 1/2 MS medium were used as control. The leaf discs of PD1-PD9 and CaMV35S transgenic plants were then incubated in staining solution at $37^{\circ} \mathrm{C}$ for $3 \mathrm{~h}$. Finally, the samples were observed and photographed after decolorization. (JPG $2139 \mathrm{~kb}$ )

Additional file 7: Figure S6. GUS staining of detached leaves of Nicotiana benthamiana transgenic plants under normal and low-temperature conditions. Ninety leaf discs (diameter $0.5 \mathrm{~cm}$ ) from fifteen 60-day-old individual plants (5 individual plants/line, 3 lines for each construct) of PD1-PD9 and CaMV35S transgenic plants were incubated in liquid $1 / 2 \mathrm{MS}$ medium at $4^{\circ} \mathrm{C}$ for $3,6,12$, 24,48 , and $72 \mathrm{~h}$; leaf discs floated in liquid $1 / 2 \mathrm{MS}$ medium at $25^{\circ} \mathrm{C}$ were used as control. The leaf discs of PD1-PD9 and CaMV35S transgenic plants were then incubated in staining solution at $37^{\circ} \mathrm{C}$ for $3 \mathrm{~h}$. Finally, the samples were observed and photographed after decolorization. (JPG $2225 \mathrm{~kb}$ )

\section{Abbreviations}

AtSCPL30: Arabidopsis thaliana serine carboxypeptidase-like 30; CaMV35S: Cauliflower mosaic virus 35S; GUS: $\beta$-glucuronidase: PEG: polyethylene glycol; SCP: Serine carboxypeptidase; SCPL: Serine carboxypeptidase-like

\section{Funding}

This work was supported by grants from Shandong Provincial key research and development program, China (2017GSF21107); Shandong Provincial Natural Science Foundation, China (ZR2016CM05) and National Key R\&D Program of China (2016YFE0200300). These funding bodies had no role in the design of the study and collection, analysis, and interpretation of data and in writing the manuscript.

\section{Availability of data and materials}

The datasets supporting the conclusions of this article are included within the article and its additional files. All plant materials were obtained from Shandong University, Jinan, China.

\section{Author contribution}

$\mathrm{KL}, \mathrm{ZD}$ and $\mathrm{KWZ}$ conceived and designed the experiments; PJ, KZ, ZD, WL, $\mathrm{SZ}$ and WC performed the experiments; PJ, WC and QH analyzed the data; $\mathrm{KL}$ contributed reagents/materials/analysis tools; $\mathrm{KL}$ and $\mathrm{QH}$ wrote the paper. All authors read and approved the manuscript.

\section{Ethics approval and consent to participate}

Not applicable

\section{Consent for publication}

Not applicable

\section{Competing interests}

The authors declare that they have no competing interests.

\section{Publisher's Note}

Springer Nature remains neutral with regard to jurisdictional claims in published maps and institutional affiliations.

\section{Author details}

${ }^{1}$ The Key Laboratory of Plant Cell Engineering and Germplasm Innovation, Ministry of Education, School of Life Science, Shandong University, Jinan, Shandong, China. ${ }^{2}$ Maize Institute of Shandong Academy of Agricultural Sciences, Jinan, Shandong, China. ${ }^{3}$ Biology Institute of Shandong Academy of Sciences, Jinan, Shandong, China.

Received: 9 July 2018 Accepted: 13 September 2018

Published online: 21 September 2018

\section{References}

1. Liu W, Yuan JS, Stewart CN Jr. Advanced genetic tools for plant biotechnology. Nat Rev Genet. 2013;14:781-93.

2. Potenza C, Aleman L, Sengupta-Gopalan C. Targeting transgene expression in research, agricultural, and environmental applications: promoters used in plant transformation. In Vitro Cell Dev Biol. 2004;40:1-22.

3. Han YJ, Kim YM, Hwang OJ, Kim Jl. Characterization of a small constitutive promoter from Arabidopsis translationally controlled tumor protein (AtTCTP) gene for plant transformation. Plant Cell Rep. 2015;34:265-75.

4. Tao YB, He LL, Niu $\sqcup$, Xu ZF. Isolation and characterization of an ubiquitin extension protein gene (JCUEP) promoter from Jatropha curcas. Planta. 2015;241:823-36.

5. Zhang H, Hou J, Jiang P, Qi S, Xu C, He Q, et al. Identification of a 467 bp promoter of maize phosphatidylinositol synthase gene (ZmPIS) which confers high-level gene expression and salinity or osmotic stress inducibility in transgenic tobacco. Front Plant Sci. 2016;7:42.

6. Hou J, Jiang P, Qi S, Zhang K, He Q, Xu C, et al. Isolation and functional validation of salinity and osmotic stress inducible promoter from the maize type-II $\mathrm{H}^{+}$-pyrophosphatase gene by deletion analysis in transgenic tobacco plants. PLoS One. 2016;11:e0154041

7. Peremarti A, Twyman RM, Gómez-Galera S, Naqvi S, Farré G, Sabalza M, et al. Promoter diversity in multigene transformation. Plant Mol Biol. 2010;73:363-78.

8. Gonzalez DO, Church JB, Robinson A, Connell JP, Sopko M, Rowland B, et al. Expression characterization of the herbicide tolerance gene Aryloxyalkanoate dioxygenase (aad-1) controlled by seven combinations of regulatory elements. BMC Plant Biol. 2018;18:14.

9. Gudynaite-Savitch L, Johnson DA, Miki BL. Strategies to mitigate transgenepromoter interactions. Plant Biotechnol J. 2009;7:472-85.

10. Chestukhina GG, Kostina LI, Mikhailova AL, Tyurin SA, Klepikova FS, Stepanov VM. The main features of bacillus thuringiensis $\delta$-endotoxin molecular structure. Arch Microbiol. 1982;132:159-62.

11. Tu J, Zhang G, Datta K, Xu C, He Y, Zhang Q, et al. Field performance of transgenic elite commercial hybrid rice expressing bacillus thuringiensis delta-endotoxin. Nat Biotechnol. 2000:18:1101-4.

12. $L i ~ H, L i ~ J, X \cup R$, Qi NR, Song F, Li L, et al. Isolation of five rice nonendosperm tissue-expressed promoters and evaluation of their activities in transgenic rice. Plant Biotechnol J. 2017. https://doi.org/10.1111/pbi.12858.

13. Christensen AH, Quail PH. Ubiquitin promoter-based vectors for high-level expression of selectable and/or screenable marker genes in monocotyledonous plants. Transgenic Res, 1996:5:213-8.

14. Cornejo MJ, Luth D, Blankenship KM, Anderson OD, Blechl AE. Activity of a maize ubiquitin promoter in transgenic rice. Plant Mol Biol. 1993;23:567-81.

15. Jang IC, Choi WB, Lee KH, Song SI, Nahm BH, Kim JK. High-level and ubiquitous expression of the rice cytochrome $\mathrm{c}$ gene $\mathrm{OsCcl}$ and its promoter activity in transgenic plants provides a useful promoter for transgenesis of monocots. Plant Physiol. 2002;129:1473-81.

16. McElroy $D$, Blowers $A D$, Jenes $B$, Wu R. Construction of expression vectors based on the rice actin 1 (Act 1 ) $5^{\prime}$ region for use in monocot transformation. Mol Gen Genet. 1991;231:150-60.

17. Odell JT, Nagy F, Chua NH. Identification of DNA sequences required for activity of the cauliflower mosaic virus 355 promoter. Nature. 1985;313:810-2.

18. Zhang $W, M c E l r o y ~ D, W u R$. Analysis of rice $A C T 15^{\prime}$ region activity in transgenic rice plants. Plant Cell. 1991;3:1155-65.

19. Azuma M, Morimoto R, Hirose M, Morita Y, Hoshino A, lida S, et al. A petalspecific InMYB1 promoter from Japanese morning glory: a useful tool for molecular breeding of floricultural crops. Plant Biotechnol J. 2016;14:354-63. 
20. Bhullar S, Datta S, Advani S, Chakravarthy S, Gautam T, Pental D, Burma PK. Functional analysis of cauliflower mosaic virus $35 \mathrm{~S}$ promoter: re-evaluation of the role of subdomains B5, B4 and B2 in promoter activity. Plant Biotechnol J. 2007:5:696-708.

21. He C, Lin Z, McElroy D, Wu R. Identification of a rice Actin2 gene regulatory region for high-level expression of transgenes in monocots. Plant Biotechnol J. 2009;7:227-39.

22. Furtado A, Henry RJ, Pellegrineschi A. Analysis of promoters in transgenic barley and wheat. Plant Biotechnol J. 2009;7:240-53.

23. Goddijn OJ, Lindsey K, van der Lee FM, Klap JC, Sijmons PC. Differential gene expression in nematode induced feeding structures of transgenic plant harbouring promoter-gusA fusion constructs. Plant J. 1993;4:863-73.

24. Urwin PE, Møller SG, Lilley CJ, McPherson MJ, Atkinson HJ. Continual green fluorescent protein monitoring of cauliflower mosaic virus 355 promoter activity in nematode-induced feeding cells in Arabidopsis thaliana. Mol Plant-Microbe Interact. 1997;10:394-400

25. Koia J, Moyle R, Hendry C, Lim L, Botella JR. Pineapple translation factor SUI1 and ribosomal protein L36 promoters drive constitutive transgene expression patterns in Arabidopsis thaliana. Plant Mol Biol. 2013;81:327-36.

26. Elmayan $T$, Vaucheret $H$. Expression of single copies of a strongly expressed 35S transgene can be silenced post-transcriptionally. Plant J. 1996;9:787-97.

27. Ho MW, Ryan A, Cummins J. Cauliflower mosaic virus promoter - a recipe for disaster? Microb Ecol Health Dis. 1999:11:194-7.

28. Hull R, Covey SN, Dale P. Genetically modified plants and the 355 promoter: assessing the risks and enhancing the debate. Microb Ecol Health Dis. 2000;12:1-5

29. Morel JB, Tepfer M. Pour une e'valuation scientifique des risques: le casdu promoteur 35S. Biofutur. 2000;201:32-5.

30. Kohli A, Griffiths S, Palacios N, Twyman RM, Vain P, Laurie D, et al. Molecular characterization of transforming plasmid rearrangements in transgenic rice reveals a recombination hotspot in the CaMV 355 promoter and confirms the predominance of microhomology mediated recombination. Plant J. 1999;17:591-601.

31. Breddam K. Serine carboxypeptidases. A review. Carlsb Res Commun. 1986;51:83-128.

32. Feng $Y$, Xue Q. The serine carboxypeptidase like gene family of rice (Oryza sativa L. ssp. japonica). Funct Integr Genomic. 2006;6:14-24.

33. Li Y, Fan C, Xing Y, Jiang $Y$, Luo L, Sun L, et al. Natural variation in GS5 plays an important role in regulating grain size and yield in rice. Nat Genet. 2011:43:1266-9.

34. Li Z, Tang L, Qiu J, Zhang W, Wang Y, et al. Serine carboxypeptidase 46 regulates grain filling and seed germination in rice (Oryza sativa L.). PLoS One. 2016;11:e0159737.

35. Liu $H$, Wang $X$, Zhang $H$, Yang $Y$, Ge $X$, Song F. A rice serine carboxypeptidase-like gene OSBISCPL1 is involved in regulation of defense responses against biotic and oxidative stress. Gene. 2008;420:57-65.

36. Kowalczyk S, Jakubowska A, Zielińska E, Bandurski RS. Bifunctional indole-3acetyl transferase catalyses synthesis and hydrolysis of indole-3-acetyl-myoinositol in immature endosperm of Zea mays. Physiol Plantarum. 2003;119: 165-74.

37. Fraser CM, Rider LW, Chapple C. An expression and bioinformatics analysis of the Arabidopsis serine carboxypeptidase-like gene family. Plant Physiol. 2005;138:1136-48

38. Lehfeldt C, Shirley AM, Meyer K, Ruegger MO, Cusumano JC, Viitanen PV, et al. Cloning of the SNG1 gene of Arabidopsis reveals a role for a serine carboxypeptidase-like protein as an acyltransferase in secondary metabolism. Plant Cell. 2000;12:1295-306.

39. Cercós M, Urbez C, Carbonell J. A serine carboxypeptidase gene (PsCP), expressed in early steps of reproductive and vegetative development in Pisum sativum, is induced by gibberellins. Plant Mol Biol. 2003;51:165-74.

40. Domínguez F, González MC, Cejudo FJ. A germination-related gene encoding a serine carboxypeptidase is expressed during the differentiation of the vascular tissue in wheat grains and seedlings. Planta. 2002;215:727-34.

41. Mugford ST, Qi X, Bakht S, Hill L, Wegel E, Hughes RK, et al. A serine carboxypeptidase-like acyltransferase is required for synthesis of antimicrobial compounds and disease resistance in oats. Plant Cell. 2009;21:2473-84.

42. Bienert MD, Delannoy M, Navarre C, Boutry M. NtSCP1 from tobacco is an extracellular serine carboxypeptidase III that has an impact on cell elongation. Plant Physiol. 2012;158:1220-9.
43. Morcuende R, Bari R, Gibon Y, Zheng W, Pant BD, Bläsing O, et al. Genomewide reprogramming of metabolism and regulatory networks of Arabidopsis in response to phosphorus. Plant Cell Environ. 2007;30:85-112.

44. Schmid M, Davison TS, Henz SR, Pape UJ, Demar M, Vingron M, et al. A gene expression map of Arabidopsis thaliana development. Nat Genet. 2005;37:501-6.

45. Higo K, Ugawa Y, Iwamoto M, Korenaga T. Plant cis-acting regulatory DNA elements (PLACE) database: 1999. Nucleic Acids Res. 1999;27:297-300.

46. Lescot M, Déhais $P$, Thijs $G$, Marchal $K$, Moreau $Y$, Van de Peer $Y$, et al. PlantCARE, a database of plant cis-acting regulatory elements and a portal to tools for in silico analysis of promoter sequences. Nucleic Acids Res. 2002;30:325-7.

47. Voelker T, Sturm A, Chrispeels MJ. Differences in expression between two seed lectin alleles obtained from normal and lectindeficient beans are maintained in transgenic tobacco. EMBO J. 1987;6:3571-7.

48. Jefferson RA, Kavanagh TA, Bevan MW. GUS fusions: beta-glucuronidase as a sensitive and versatile gene fusion marker in higher plants. EMBO J. 1987;6:3901-7.

49. Bradford MM. A rapid and sensitive method for the quantitation of microgram quantities of protein utilizing the principle of protein-dye binding. Anal Biochem. 1976;72:248-54.

50. Yang $Y$, Li R, Qi M. In vivo analysis of plant promoters and transcription factors by agroinfiltration of tobacco leaves. Plant J. 2000;22:543-51.

51. Wang Z, Chen $C, X u Y$, Jiang $R$, Han $Y, X u Z$, Chong K. A practical vector for efficient knockdown of gene expression in rice (Oryza sativa L.). Plant Mol Biol Rep. 2004:22:409-17.

52. Quan R, Shang M, Zhang H, Zhao Y, Zhang J. Improved chilling tolerance by transformation with betA gene for the enhancement of glycinebetaine synthesis in maize. Plant Sci. 2004;166:141-9.

53. Hernandez-Garcia CM, Martinelli AP, Bouchard RA, Finer JJ. A soybean (Glycine max) polyubiquitin promoter gives strong constitutive expression in transgenic soybean. Plant Cell Rep. 2009;28:837-49.

54. Xiao K, Zhang C, Harrison M, Wang ZY. Isolation and characterization of a novel plant promoter that directs strong constitutive expression of transgenes in plants. Mol Breeding. 2005:15:221-31.

55. Yanagisawa S. Dof domain proteins: plant-specific transcription factors associated with diverse phenomena unique to plants. Plant Cell Physiol. 2004;45:386-91.

56. Yanagisawa S, Schmidt RJ. Diversity and similarity among recognition sequences of Dof transcription factors. Plant J. 1999;17:209-14.

57. Yanagisawa S. Dof1 and Dof2 transcription factors are associated with expression of multiple genes involved in carbon metabolism in maize. Plant J. 2000;21:281-8.

58. Christensen AH, Sharrock RA, Quail PH. Maize polyubiquitin genes: structure, thermal perturbation of expression and transcript splicing, and promoter activity following transfer to protoplasts by electroporation. Plant Mol Biol. 1992;18:675-89.

59. Kai S, Mendel RR. Quantitative transient gene expression: comparison of the promoters for maize polyubiquitin1, rice actin1, maize-derived emu and CaMV35S in cells of barley, maize and tobacco. Transgenic Res. 1994;3:249-55.

Ready to submit your research? Choose BMC and benefit from:

- fast, convenient online submission

- thorough peer review by experienced researchers in your field

- rapid publication on acceptance

- support for research data, including large and complex data types

- gold Open Access which fosters wider collaboration and increased citations

- maximum visibility for your research: over $100 \mathrm{M}$ website views per year

At $\mathrm{BMC}$, research is always in progress.

Learn more biomedcentral.com/submission 